\title{
Bracken growth, toxin production and transfer from plant to soil: a 2-year monitoring study
}

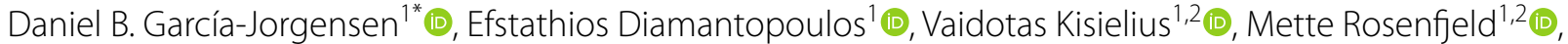 \\ Lars H. Rasmussen² ${ }^{2}$, Bjarne W. Strobel ${ }^{1}\left[\right.$ and Hans Chr. B. Hansen ${ }^{1}[\mathbb{C}$
}

\begin{abstract}
Background: Bracken fern (Pteridium aquilinum) produces several toxic glycosides, of which ptaquiloside (PTA) is the most well documented. PTA is released from bracken to soil and leaches to surface water and to groundwater. This study presents the first comprehensive monitoring study of bracken biomass, PTA content in the biomass, release by precipitation and concentrations in soil solution at $50 \mathrm{~cm}$ depth. Laboratory experiments were carried out to estimate the degradation kinetics of PTA in different soil horizons and moisture contents.

Results: The PTA concentration in bracken was highest at the earliest development stages of the plant, i.e., May, declining through the growing season until negligible contents at senescence. The maximum seasonal PTA content in the canopy peaked in early summer, with values up to $1600 \mathrm{mg} \mathrm{m}^{-2}$. Results show that on average $0.2 \%$ of the PTA present in the canopy is washed per mm of incident rain, resulting in up to $13.1 \mathrm{mg} \mathrm{PTA} \mathrm{m}^{-2}$ being washed off during single rain events. Once in the soil, PTA dissipates rapidly showing a half-lives ranging from 3.3 to $73 \mathrm{~h}$ with observed degradation rates showing a tenfold decrease with soil depths increasing from top soil to $25 \mathrm{~cm}$ soil depth. Concentrations of PTA in soil solution were positively correlated with the content of PTA in the canopy, with maximum pore water concentrations up to 4,820 $\mathrm{ng} \mathrm{L}^{-1}$ during a pulse event taking place in July 2019.

Conclusions: The production of PTA in bracken was found to be proportional to biomass growth, while the mass of PTA being released is a function of volume and intensity of precipitation, as well as the bracken development stage. Leaching of PTA takes place in the form of pulses linked to precipitation events, with concentrations in the soil solution exceeding levels which are known to pose a risk to human health.
\end{abstract}

Keywords: Phytotoxins, Monitoring, Emerging pollutants, Ptaquiloside, Bracken fern, Production, Release, Leaching

\section{Background}

Plants produce a wide array of secondary metabolites essential for physiological processes and defence against stressors, such as competing plants or pests. These compounds are often polar and mobile, some of them toxic and a few are present in remarkably high amounts in the plant biomass. Studies during the last two decades

\footnotetext{
*Correspondence: daja@plen.ku.dk

${ }^{1}$ Department of Plant and Environmental Sciences, University

of Copenhagen, Thorvaldsensvej 40, 1871 Frederiksberg, Denmark

Full list of author information is available at the end of the article
}

have increased the awareness of phytotoxins as emerging aquatic micropollutants [1-3], as some of these have been detected in soil and water near toxin producing plants [4-6].

The presence of phytotoxins in the environment has raised questions on how toxins are mobilized from the plant to the environment. Several release pathways of phytotoxins into the environment have been identified such as leaf wash off, stem-flow wash off, root exudation and decay of plant material $[7,8]$. However, there is still a lack of understanding in the underlying mechanisms that

\section{Springer Open}

(c) The Author(s) 2021. This article is licensed under a Creative Commons Attribution 4.0 International License, which permits use, sharing, adaptation, distribution and reproduction in any medium or format, as long as you give appropriate credit to the original author(s) and the source, provide a link to the Creative Commons licence, and indicate if changes were made. The images or other third party material in this article are included in the article's Creative Commons licence, unless indicated otherwise in a credit line to the material. If material is not included in the article's Creative Commons licence and your intended use is not permitted by statutory regulation or exceeds the permitted use, you will need to obtain permission directly from the copyright holder. To view a copy of this licence, visit http://creativeco mmons.org/licenses/by/4.0/. 
control the release of phytotoxins from the plant, which is critical to assess the risk of these emerging aquatic micropollutants.

Bracken fern is a complex genus of Pteridaceae comprising several species, subspecies and varieties, present in all continents except Antarctica [9]. This fern genus is viewed in many places as a weed and its abundance has been related to changes in land use. Bracken can grow vigorously, and often appears as the dominant species when present, with maximum recorded biomasses up to $1408 \mathrm{~g} \mathrm{~m}^{-2}$ [10]. The production of aboveground biomass is supported by a well-developed rhizome system with a weight generally higher than the aboveground biomass. In bracken infested areas in UK, the rhizome dry biomass has been estimated to reach values up to $5.14 \mathrm{~kg} \mathrm{~m}^{-2}$ [11].

Bracken produces large amounts of toxic compounds, where some of these compounds exert allelopathic effects on other plant species [12, 13]. Furthermore, the International Agency for Research on Cancer (IARC) WHO/ IARC has classified bracken fern in group $2 \mathrm{~B}$, as possibly carcinogenic to humans, based on the evidence in experimental animals [14]. From all the toxic compounds produced by bracken, ptaquiloside (PTA), an illudane glycoside, has been identified as the main responsible for the carcinogenicity of bracken fern (Table 1$)[15,16]$.

Previous studies have detected other glycosides in bracken such as caudatoside (CAU), ptesculentoside (PTE) and ptaquiloside $\mathrm{Z}$ [17-20]. The total illudane glycoside content measured in bracken was up to $13.0 \mathrm{mg} \mathrm{g}^{-1}$, with different ratios between PTA, PTE and CAU observed as a function of geographical region [21].
However, PTA was the prevalent illudane glycoside produced by Scandinavian bracken. Ptaquiloside has been detected in soil and water in bracken infested areas, with concentrations up to $73,000 \mathrm{ng} \mathrm{g}^{-1}$ in soils, $92 \mathrm{ng} \mathrm{L}^{-1}$ in shallow groundwater and $2,280 \mathrm{ng} \mathrm{L}^{-1}$ in stream water $[4,22,23]$. There are different mechanisms for release of PTA from the plant, with PTA washed off by precipitation suggested to be the most important. For instance, concentrations of PTA up to $169 \mu \mathrm{g} \mathrm{L}^{-1}$ in the leaf wash off collected during precipitation events have been measured $[24,25]$. To put concentrations into perspective, the maximum tolerable concentration of PTA in drinking water has been estimated to $0.5-16 \mathrm{ng} \mathrm{L}^{-1}$ [26].

Ptaquiloside is highly hydrophilic and weakly sorbing, implied by an log octanol-water partition coefficient $\left(K_{\text {OW }}\right)$ value of -0.63 [26] (Table 1$)$. Ptaquiloside dissipates in soils into pterosin B (PTB) by both microbial degradation and hydrolysis, with half-lives between 8 and $180 \mathrm{~h}$ depending on the type of soil material [26, 27]. Hydrolysis of PTA is strongly $\mathrm{pH}$ dependent, with lower degradation rates found at slightly acidic to neutral conditions [28]. PTB dissipates in the soil at a slower rate than PTA, by both microbial degradation and irreversible sorption to soil components such as clay and organic matter [29]. Based on wide occurrence of PTA in the environment, several authors have identified PTA as a potential aquatic micropollutant due to its toxicity, high content in bracken, release in high concentrations, high solubility and the widespread presence of bracken $[3,24$, 30, 31].

Production of PTA in bracken is influenced by environmental factors, plant varieties or induced stress by

Table 1 Structure and physicochemical properties for ptaquiloside (PTA) and pterosin B (PTB)

\begin{tabular}{lll}
\hline & Ptaquiloside & Pterosin B \\
\hline CAS number & $87,625-62-5$ & $34,175-96-7$ \\
$218.29 \mathrm{~g} \mathrm{~mol}^{-1}$ \\
Molar mass
\end{tabular}

\footnotetext{
a Rasmussen et al. 2005 [29]

b EpiSuite: accessed November 2020
} 
human management activities [20, 22, 32]. The concentration of PTA in bracken is maximum at emergence, with recorded contents up to $37 \mathrm{mg} \mathrm{g}^{-1}$ in bracken tissue $[22,27]$. From the moment of emergence, PTA concentrations in bracken decline progressively through the growing season [21,33]. The total PTA content in the biomass recorded is usually in the order of $\mathrm{mg} \mathrm{m}^{-2}$, with recorded values up to $590 \mathrm{mg} \mathrm{PTA} \mathrm{m}^{-2}$ in bracken from Scotland [31].

A previous study by Garcia-Jorgensen et al. introduced a novel modelling concept for predicting the environmental fate of natural toxins using the mechanistic model DAISY [30]. Toxin production rates and release of PTA from bracken were identified as the processes with the highest uncertainty, due to the lack of a comprehensive dataset for calibration of the model. The present study aims to characterize key PTA pathways from bracken to soil, with specific focus on: (i) PTA generation in bracken, (ii) PTA wash off from the canopy by precipitation, (iii) soil solution PTA concentrations, (iv) PTA degradation kinetics in the soil, and (v) link between release events and soil solution concentrations. For this, we performed a 2-year monitoring program focusing on bracken biomass, PTA concentration in plant, and soil water concentrations at $50 \mathrm{~cm}$ depth. Moreover, we carried spot field experiments targeting release events and batch laboratory experiments to determine PTA degradation in soils. To the best of our knowledge, this study presents the first comprehensive longer-term dataset regarding PTA dynamics in bracken fern and soil.

\section{Materials and methods \\ Site description}

The monitoring study was carried out in Humleoreskov, a temperate forest located $60 \mathrm{~km}$ west of Copenhagen, Denmark (N $55^{\circ} 28^{\prime} 29.7^{\prime \prime}$ E $11^{\circ} 54^{\prime} 26.1^{\prime \prime}$, Fig. 1a). The study area is located inside a forest glade dominated by bracken and surrounded by deciduous tree species such as European beech (Fagus sylvatica L.) and Common oak (Quercus robur L.) (Fig. 1a, b). In the area, bracken is present in form of dense stands in forest glades composed almost exclusively of bracken, as well as forest floor vegetation at a lower density. Bracken completely covers all surface with high density, with a homogeneous canopy surpassing two meters height when fully developed. The criteria for selecting the area was to have a minimal disturbance from the tree canopy on precipitation, a flat
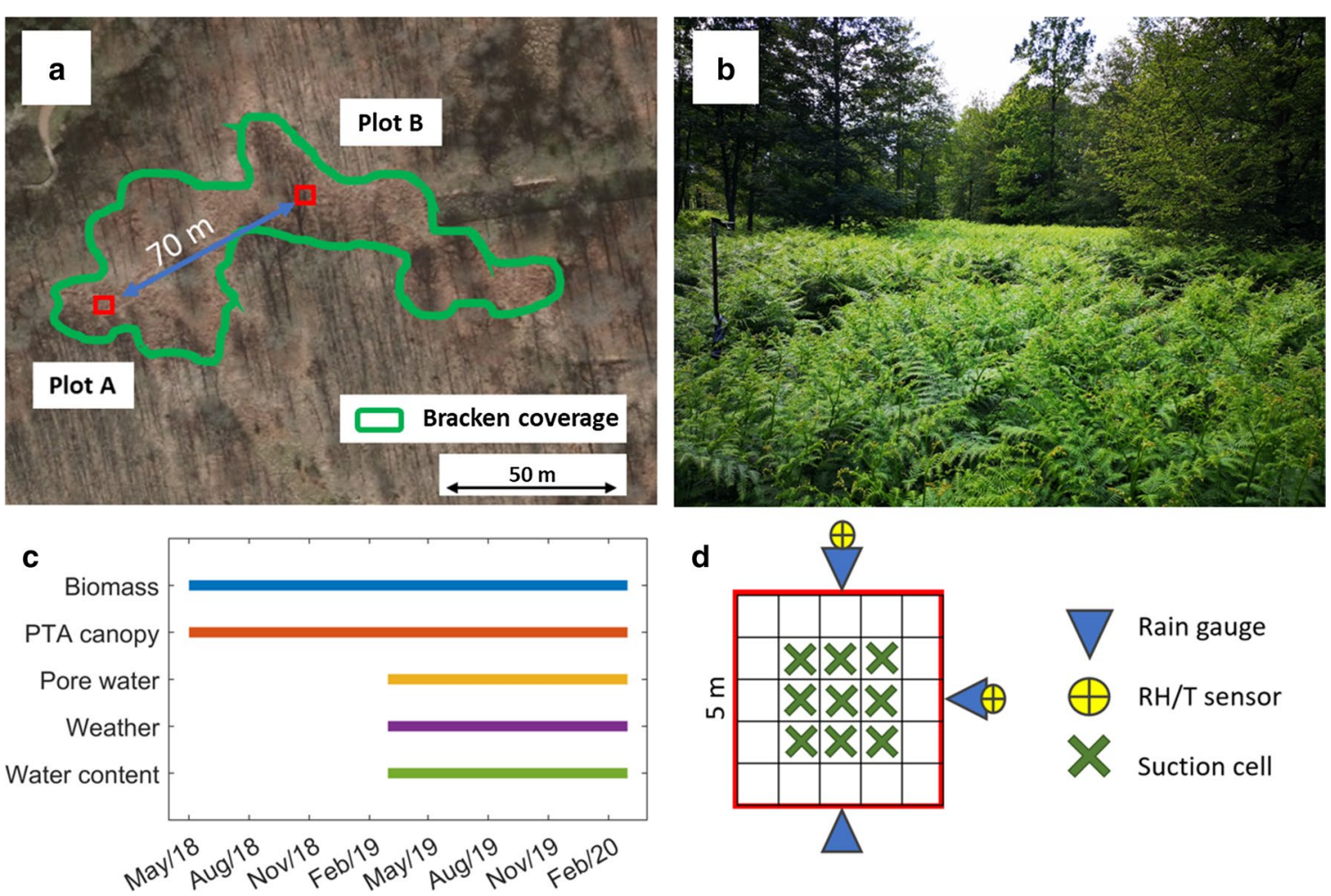

Fig. 1 a Aerial picture of the study area of the monitoring plots. b Photo of B-plot in June 2019 (Photo by Daniel Garcia Jorgensen). c Start and end date of the different variables monitored. $\mathbf{d}$ Set up of rain collectors, relative humidity/temperature sensors and suction cells in the B monitoring plot 
topography, and homogeneous bracken biomass in the plot (Fig. 1b).

Humleore's soil is categorized as sandy loam by the United States Department of Agriculture (USDA) classification and identified as an Oxyaquic Hapludalf in the USDA soil taxonomy [34, 35]. The soil is composed of morainic till with a content of clay and silt in deeper horizons up to 18 and 26\%, respectively. The soil presents $\mathrm{pH}$ values ranging from 4.3 at the surface to 6.9 at $36 \mathrm{~cm}$ depth. For a more detailed description of the soil profile, horizons and physicochemical characteristics, the reader is referred to Additional file 1: Section 2.

\section{Field monitoring and laboratory experiments}

The monitoring began in May 2018 and finished in March 2020 (Fig. 1c). For the entire period, the frequency of sampling ranged from 1 to 3 weeks, depending on the time of the year. High frequency sampling of plant material and soil pore water was centered in the period from beginning of the growing season until the full transition of bracken into litter, i.e., from May to December.

Two different plots of each $25 \mathrm{~m}^{2}$ each were set in the forest glade, with $5 \mathrm{~m}$ side length, located in the center of the forest glade. Plots were separated by approximately $70 \mathrm{~m}$ from each other (Fig. 1a, d). Moreover, each plot was divided into 25 subplots of $1 \mathrm{~m}^{2}$ each for sampling purposes. Bracken biomass and PTA content was measured in both plots, while PTA in pore water, soil water content and climate variables (temperature, relative humidity, precipitation) were only monitored in B-plot (Fig. 1b, d). Different sensors were set in the borders of the $\mathrm{B}$ plot to monitor precipitation, temperature and relative humidity. Moreover, nine suction cells were installed at $50 \mathrm{~cm}$ depth in the center of the plot in March of 2019 to sample soil solution under bracken canopy for the entire calendar year (Fig. 1d).

\section{Environmental variables}

From March 2019 until March 2020, precipitation, relative humidity and temperature were constantly monitored on-site (Fig. 1d). Precipitation was measured using three rain collectors comprising a Pronamic Rain-OMatic small rain gauge (Ringkoebing, Denmark) coupled with an ONSET HOBO ${ }^{\circledR}$ Pendant ${ }^{\circledR}$ Event Data Logger (Bourne, USA). The rain collectors were installed on poles placed in the middle of three different sides of the plot, at $250 \mathrm{~cm}$ height and above the bracken canopy (Fig. 1b). Temperature and relative humidity were monitored with two ONSET ${ }^{\circledR} H O B O^{\circledR}$ External Temperature/ $\mathrm{RH}$ Sensor Data Loggers (Bourne, USA). For measuring the water content in the soil profile, three Delta-T PR2 soil profile probes were installed at $100 \mathrm{~cm}$ depth in the
B-plot. Measurements were carried out with a Delta-T HH2 Moisture Meter (Cambridge, UK).

\section{Bracken biomass}

During the entire monitoring period, bracken biomass was monitored in plots A and B (Fig. 1a) comprising a total of 22 sampling days. In each sampling day, a total of six different subplots were sampled for bracken biomass, three from each plot. All subplots to be sampled were randomly selected at the beginning of each season.

For each subplot and measuring day, the number of fronds, frond height, number of pinnae and pinna length were determined on-site. One frond from the most representative class was collected from each subplot. This was selected visually considering height and apparent biomass of all fronds for the specific subplot. The length of the second and third pinnae of the selected frond were also measured on site. The collected fronds were placed in plastic bags and kept on ice for up to two hours until arrival to the laboratory. Once in the laboratory, the diameter of the rachis, as well as the weight of the frond, pinna and rachis were determined separately. The total aboveground biomass per square meter was calculated as the sum of pinna and rachis biomass, multiplied by the number of fronds in each plot. In the 2019 growing season, the monitoring of biomass halted at the end of July as a heavy storm tilted the bracken, making it impossible to continue monitoring of the number of fronds.

Moreover, below-ground biomass was determined once on 1st July of 2020, at the time of frond maturity. For that, three plots of $0.5 \times 2.0 \mathrm{~m}$ were established at 20-60 m west-southwest of the B-plot (Fig. 1a). Each plot was then excavated until no further rhizomes were found for $20 \mathrm{~cm}$. The soil was removed from the rhizomes, washed and divided into frond-bearing and storage rhizomes based on the occurrence of short-shots (frondbearing only). The length of all rhizome-fragments was measured and the number of terminal buds counted. The dry-matter content was determined after drying for $48 \mathrm{~h}$ at $110{ }^{\circ} \mathrm{C}$ in a fan-ventilated oven. For more details regarding the morphology of bracken and calculation of the biomass, the reader is referred to Additional file 1: Sections 1 and 6, respectively.

\section{PTA in the canopy}

Initially, the pinna and rachis were separated with common scissors. Then, bracken pinnae were cut into 5-10 $\mathrm{cm}$ pieces, mixed by hand and a subsample of approximately 15 gr stored in a plastic bag. Rachis used for PTA determination was cut longitudinally in pieces with an approximate length of $10 \mathrm{~cm}$ and placed in plastic bags. Thereafter, all plant samples were stored at $-80{ }^{\circ} \mathrm{C}$ until sample preparation. 


\section{Soil pore water}

From March 2019, pore water was monitored for one full calendar year (Fig. 1c). Nine Prenart Super Steel suction cells (Frederiksberg, Denmark), with a dimension of $110 \mathrm{~mm}$ length, $19.5 \mathrm{~mm}$ outer diameter, porous area of $40 \mathrm{~cm}^{2}$ and an average pore size of $50 \mathrm{~nm}$ were used. The suction cells were installed at approximately $50 \mathrm{~cm}$ depth and at an angle of 45 degrees to minimize disturbance of the soil column above the cell. Suction cells were connected to $100 \mathrm{~mL}$ glass collector bottles on the soil surface via $2 \mathrm{~mm}$ PTFE tubing. Between sampling days, vacuum was applied with a hand vacuum pump until a pressure of $-20 \mathrm{kPa}$ was reached. At the time of sampling, the content in the bottle was emptied, followed by the application of a vacuum of $-60 \mathrm{kPa}$ for the extraction of fresh soil pore water. A subsample, if possible, of $10 \mathrm{~mL}$ was transferred to $15 \mathrm{~mL}$ polypropylene conical centrifuge tubes. Samples were immediately stored on ice, for a time up to $2 \mathrm{~h}$, until arrival at the laboratory. Afterwards, samples were preserved by adding $0.5 \mathrm{~mL}$ of $0.3 \mathrm{M}$ ammonium acetate buffer per $20 \mathrm{~mL}$ of sample, following the protocol of Clauson-Kaas et al. [24]. Thereafter, the samples were immediately stored at $-18{ }^{\circ} \mathrm{C}$ until sample purification.

\section{PTA release}

For quantification of the PTA being released by precipitation, we sampled the throughfall water under bracken, i.e., intercepted rainwater dripping off the canopy, during four precipitation events. The precipitation events that were monitored took place in 25th and 30th of August 2018, and 5th and 30th July of 2019. For collecting the throughfall water, glass jars were placed randomly under the bracken canopy prior to the precipitation event. The jars were cylindrical with an opening diameter of $8 \mathrm{~cm}$. Moreover, a plastic mesh with grid size of $1.1 \mathrm{~mm}$ was placed on the openings of the jars to avoid plant materials entering the container. Prior to the rain event, $2 \mathrm{~mL}$ of $0.3 \mathrm{M}$ ammonium acetate buffer was added to each container to minimize PTA degradation until collection of the sample [36]. A total of 9 (2018) or 12 (2019) jars were placed in the middle of the B plot, with the same distribution pattern than suction cells in the soil (Fig. 1d). However, during the precipitation event taking place on 30th July 2019, a total of 9 jars were placed in both plots A and $\mathrm{B}$, to determine the variation in wash off amount between plots. The mass of PTA washed off the canopy during a precipitation event $\left(\mathrm{mg}\right.$ PTA m${ }^{-2}$ ) was calculated as the concentration of PTA measured in throughfall water $(\mathrm{mg}$ $\mathrm{L}^{-1}$ ), multiplied by the volume of throughfall water collected in the glass containers (L) and divided by the area of the jar $\left(\mathrm{m}^{2}\right)$.

\section{Degradation of PTA in soil}

We conducted 6 rounds of batch experiments estimating PTA degradation kinetics for the three uppermost horizons of the soil, i.e. $\mathrm{A}_{1}, \mathrm{~A}_{2}$ and $\mathrm{AE}$ horizons. For this, a soil profile was excavated under bracken canopy near plot B. Moreover, we tested the influence of soil moisture content on PTA degradation kinetics, by carrying out incubations in both unsaturated (matric potential of $-100 \mathrm{~cm}$ or $\mathrm{pF} 2$ ) and near saturated (matric potential of $-10 \mathrm{~cm}$ or $\mathrm{pF} 1$ ) conditions. An aliquot of PTA solution was added to the soil samples to reach an initial concentration of $10 \mu \mathrm{g} \mathrm{g}^{-1}$ dry weight (DW). The stock solution of PTA used for addition was concentrated bracken extract purified by preparative HPLC with a Perkin Elmer Series 10 liquid chromatograph (Connecticut, USA) equipped with a Shimadzu SPD-10A UV-VIS Detector (Kyoto, Japan). The purification followed the method by Rasmussen et al. [26]. For more detailed information of the standards use and the procedure followed see Additional file 1: Section 5.1.

After the soil water mixture was homogenized, an aliquot equivalent to $2 \mathrm{~g}$ DW was added into $15 \mathrm{~mL}$ centrifuge vials. Three different replicates were prepared for each sampling time, making a total of 180 samples incubated during the experiment. All samples were stored on ice during sample preparation to avoid degradation. Thereafter, samples were placed in a climate chamber at $10{ }^{\circ} \mathrm{C}, 70 \%$ humidity and darkness. To avoid anaerobic conditions, the tubes were incubated covered with aluminum foil. The samples were left undisturbed throughout the experiment until the moment of extraction and analysis.

The PTA degradation kinetic data were fitted as a pseudo first-order reaction with respect to PTA. TableCurve $2 D$ v. 5.01 software was used (Jandel Scientific, USA) for non-linear regression. The nominal initial concentration at time 0 was not included in the regression analysis but was estimated by regression. The values are expressed as degradation, as sorption of PTA is negligible compared with microbial degradation [26, 27, 37].

\section{PTA determination methods \\ Solvents and chemicals}

HPLC-grade methanol for bracken extraction and determination of PTA in bracken was obtained from SigmaAldrich (Denmark). HPLC-grade hexane was obtained from VWR (HiPerSolv Chromanorm, Denmark). LC-MS grade methanol was obtained from Honeywell ( $L C-M S$ Chromasolv, Germany), while LC-MS grade acetonitrile was obtained from Merck Millipore (LC-MS LiChrosolv hypergrade, Germany). All acids and bases (sodium hydroxide, formic and trifluoroacetic acid) were analytical grade obtained from Sigma-Aldrich (Denmark). 
Polyamide was obtained from Sigma-Aldrich (Polyamide for column chromatography 6, Denmark). Loganin used as internal standard was purchased from Sigma-Aldrich (Denmark).

\section{PTA determination in bracken tissue samples}

Frozen plant samples for PTA determination were freeze dried in a Labogene Scanvac Cool Safe freezer dryer, at $1 \mathrm{hPa}$ and $-96^{\circ} \mathrm{C}$ for $48 \mathrm{~h}$. The freeze-dried samples, both pinna and rachis, were milled into a fine powder in a Kenwood KVC3100 W kitchen machine adapted with a Kenwood Multi Mill attachment. For extraction, an aliquot of $0.5 \mathrm{~g}$ of powder was placed into polyethylene centrifuge tubes of $50 \mathrm{~mL}$, followed by the addition of $20 \mathrm{~mL}$ of $80 \% \mathrm{v} / \mathrm{v}$ methanol into the centrifuge tubes and shaking for $20 \mathrm{~min}$. For extraction, both methanol and ethanol were tested, and methanol was selected because it showed a better extraction efficiency. Thereafter, the tubes were centrifuged at $20,000 \mathrm{~g}$ and $4{ }^{\circ} \mathrm{C}$ for $15 \mathrm{~min}$. The supernatant was transferred to another centrifuge tube and kept on ice. Then, an aliquot of $4 \mathrm{~mL}$ of the extract was filtered through a $0.45 \mu \mathrm{m}$ regenerated cellulose (RC) syringe filter (Sigma-Aldrich, Denmark) into a $15 \mathrm{~mL}$ centrifuge tube. For removal of pigments, $4 \mathrm{~mL}$ of hexane was added. The tube was shaken by hand for $10 \mathrm{~s}$ and the two phases then allowed to separate. The methanol phase was transferred to a $15 \mathrm{~mL}$ centrifuge tube using a Pasteur pipette. The cleaning with hexane was repeated twice, to remove as much interfering substances as possible. Thereafter, $2 \mathrm{~mL}$ of the methanolic extract was diluted with DI to reach a $40 \%$ methanol solution, filtered with a $0.22 \mu \mathrm{m}$ PTFE syringe filter into a $1.5 \mathrm{~mL}$ $\mathrm{LC}$ amber vial and stored on ice until analysis. All samples were done in duplicates. Extraction and analysis of all samples were carried out in the same day.

The method for quantification of PTA and PTB was adapted from the method of Ayala-Luis et al. and Rasmussen and Pedersen [28, 38]. Quantification of PTA and PTB in bracken extracts took place on an Agilent 1200 series diode array detector (DAD) HPLC system equipped with a Phenomenex Hyperclone C8-DBS $(150 \mathrm{~mm} \times 4.6 \mathrm{~mm}, 3 \mu \mathrm{m})$ column thermostated at $35^{\circ} \mathrm{C}$; a Phenomenex Gemini C6-Phenyl guard column was used. The analytes were separated with a mobile phase composed of $10 \%$ acetonitrile (eluent A) and $100 \%$ acetonitrile (eluent $\mathrm{B}$ ). The elution gradient was: $0-6 \mathrm{~min}$ $11 \%$ B, 7 min $47 \%$ B, $7-10 \min 47 \%$ B, 11 min $11 \%$ B, and $11-13 \min 11 \% \mathrm{~B}$. The sample injection volume was 50 $\mu \mathrm{L}$. UV detection was performed at $214 \mathrm{~nm}$ for PTA and $220 \mathrm{~nm}$ for PTB. All samples were prepared in duplicates.

The LOD and LOQ of the method for PTA was 82 and $276 \mu \mathrm{g} \mathrm{g}^{-1}$, respectively, while for PTB it was 16 and $55 \mu \mathrm{g} \mathrm{g}^{-1}$. The LOD and LOQ for PTA was calculated as
3 and 10 times the standard deviation of the injection of the lowest standard for all runs, divided by the average slope of the calibration curves. Since PTB is present in low amounts in the canopy and assumed to not be produced in the plant but formed as degradation of PTA (Additional file 1: Figure S13), we decide to proceed with molar sum as a calculation of the total PTA produced $\left(\mathrm{PTA}_{\mathrm{TOT}}\right)$. The final concentration of $\mathrm{PTA}_{\mathrm{TOT}}$ in each sample was obtained adding the measured concentration of PTA and PTB, applying 1:1 molar conversion ratio from PTA to PTB. For calculation of the PTA ${ }_{\text {TOT }}$ after the storm in July 2019, e.g., without information regarding the number of fronds, it was assumed that the number was equal to that measured the last sampling date. For more information regarding calculations of toxin in the biomass, the reader is referred to Additional file 1: Section 7.

\section{PTA determination in soil solution}

Soil water samples were purified and concentrated by solid phase extraction (SPE) using Waters Oasis MAX ( 1 cc Flangeless Vac Cartridge, $10 \mathrm{mg}$, USA) using a SPE method adapted from Skrbic et al. [39]. The SPE cartridges were conditioned consecutively with $0.33 \mathrm{~mL}$ of $100 \%$ methanol and $0.33 \mathrm{~mL}$ of deionized water, with the cartridges running dry for $20 \mathrm{~s}$ between additions. A total of $3 \mathrm{~mL}$ of sample was loaded to each SPE, by consecutive $1 \mathrm{~mL}$ additions. The cartridges were washed with $0.33 \mathrm{~mL}$ of deionized water, eluted with $1 \mathrm{~mL}$ of $100 \%$ methanol and the eluate collected into $1.5 \mathrm{~mL} \mathrm{LC}$ amber vials. The methanol in the samples was then evaporated in a heat block (Mikrolab Aarhus, Denmark), thermostated at $30{ }^{\circ} \mathrm{C}$, with a gentle air flow. After evaporation, the eluate was dissolved in $40 \%$ methanol $+0.1 \mathrm{M}$ ammonium acetate solution, buffered at pH 5 [17]. For ensuring the recovery of all compounds in the vial, these were shaken on a vortex shaker for approximately $10 \mathrm{~s}$. The solution was then transferred to a LC amber vial of 200 $\mu \mathrm{L}$ and stored at $-20^{\circ} \mathrm{C}$ until analysis.

The method used for quantification is adapted from Kisielius et al. [17]. The chromatographic separation and quantification of analytes were performed using Agilent 1260 Infinity HPLC system equipped with an Agilent 6130 Single Quadrupole mass spectrometer. The LC system was thermostated at $35{ }^{\circ} \mathrm{C}$ and with a flow of $1 \mathrm{~mL} \mathrm{~min}^{-1}$. The analytes were separated with a mobile phase comprising LC-MS-grade water (eluent A) and acetonitrile (eluent B), both containing $0.1 \%$ formic acid. The gradient of elution was: $0-1 \mathrm{~min} 20 \% \mathrm{~B}, 4.5 \mathrm{~min} 52 \%$ B, $5 \min 95 \%$ B, $5-5.5 \min 95 \%$ B, $5.6 \min 20 \%$ B, and $5.6-6$ min $20 \%$ B. The column was flushed for a minute with $11 \% \mathrm{~B}$ at end of each run, with a total time of analysis of $7 \mathrm{~min}$. The injection volume was $20 \mu \mathrm{L}$, including 
$2 \mu \mathrm{L}$ of internal standard. Loganin was used as an internal standard in all determinations, by the addition of 2 $\mu \mathrm{L}$ of $500 \mu \mathrm{g} \mathrm{L}^{-1}$ solution into each sample by the sampling robot connected to the LC instrument [36]. The mass spectrometer operated in single ion mode, targeting $219.1 \mathrm{~m} / \mathrm{z}$ fragments for both PTA and PTB [17]. Total ion scans were included for the $\mathrm{m} / \mathrm{z}$ window between 200 and 460.

The LOD and LOQ of the analytical method for PTA with external standards, including preconcentration, was 14.7 and $45.3 \mathrm{ng} \mathrm{L}^{-1}$, respectively. On the other hand, the LOD and LOQ for PTB was 2 and $6 \mathrm{ng} \mathrm{L}^{-1}$, respectively. The recovery of the full method, including preconcentration, was $74.3 \pm 0.02 \%$ and $99.6 \pm 0.03 \%$ for PTA and PTB, respectively. For handling of the results, in cases where a signal at the specific retention time of PTA or PTB was recorded, but with areas below the LOQ, the concentrations were set at half of the LOQ. In cases where no signal was detected, the concentration was set at half of the LOD.

For quality control, a positive and a negative sample was extracted with SPE as any other field sample every 15 samples. Positive sample was composed of a solution of PTA and PTB with known concentration, while the negative was a field blank from a soil in Humleore without bracken presence (Additional file 1: Section 8). All determinations were performed using purified external standards with known concentrations provided by Vaidotas Kisielius [17]. No matrix effect nor instrumental drift were identified. Analysis and visualization of results were done in MATLAB version R2020b (MathWorks, USA).

\section{PTA determination in soil}

The extraction of PTA from soils was carried out following the method by Jensen et al. [23]. After extraction, PTA was converted to PTB using the method by Rasmussen and Pedersen [38]. First, $6 \mathrm{~mL}$ of deionized water was added to each sample tube, followed by shaking on a flatbed shaker for $10 \mathrm{~min}$ at $18 \mathrm{~Hz}$. After shaking, samples were centrifuged at $20,000 \mathrm{~g}$ at $1{ }^{\circ} \mathrm{C}$ for $10 \mathrm{~min}$. The supernatant was then filtered through a RC syringe filter of $0.2 \mu \mathrm{m}$. However, the top horizons had to be filtered with $0.45 \mu \mathrm{m}$ instead, due to clogging of the filter by the organic-rich topsoil materials. The cleaning up of impurities and PTB in the extract was done by passage through solid phase extraction columns dry packed with polyamide. The PTA in the filtered extract was then converted to PTB by stepwise addition of $75 \mu \mathrm{L}$ of sodium hydroxide $(1 \mathrm{M})$ and $75 \mu \mathrm{L}$ of trifluoroacetic acid $(2.5 \mathrm{M})$ [38]. Samples were stored at $-18{ }^{\circ} \mathrm{C}$ until HPLC analysis. PTB concentrations were analyzed by HPLC using the same analytical instrument used for PTA and PTB in bracken samples ("PTA determination in bracken tissue samples" section) but with optimized settings for the chromatographic separation of PTB. The analytes were separated with a mobile phase composed of 43:57 water: acetonitrile. Flow of $1 \mathrm{~mL} \mathrm{~min}{ }^{-1}$ and $50 \mu \mathrm{L}$ of injection volume. The LOD and LOQ of the analytical method for PTB was 8.3 and $28 \mu g \mathrm{~L}^{-1}$, respectively. For more details, the reader is referred to Additional file 1: Section 5.1.

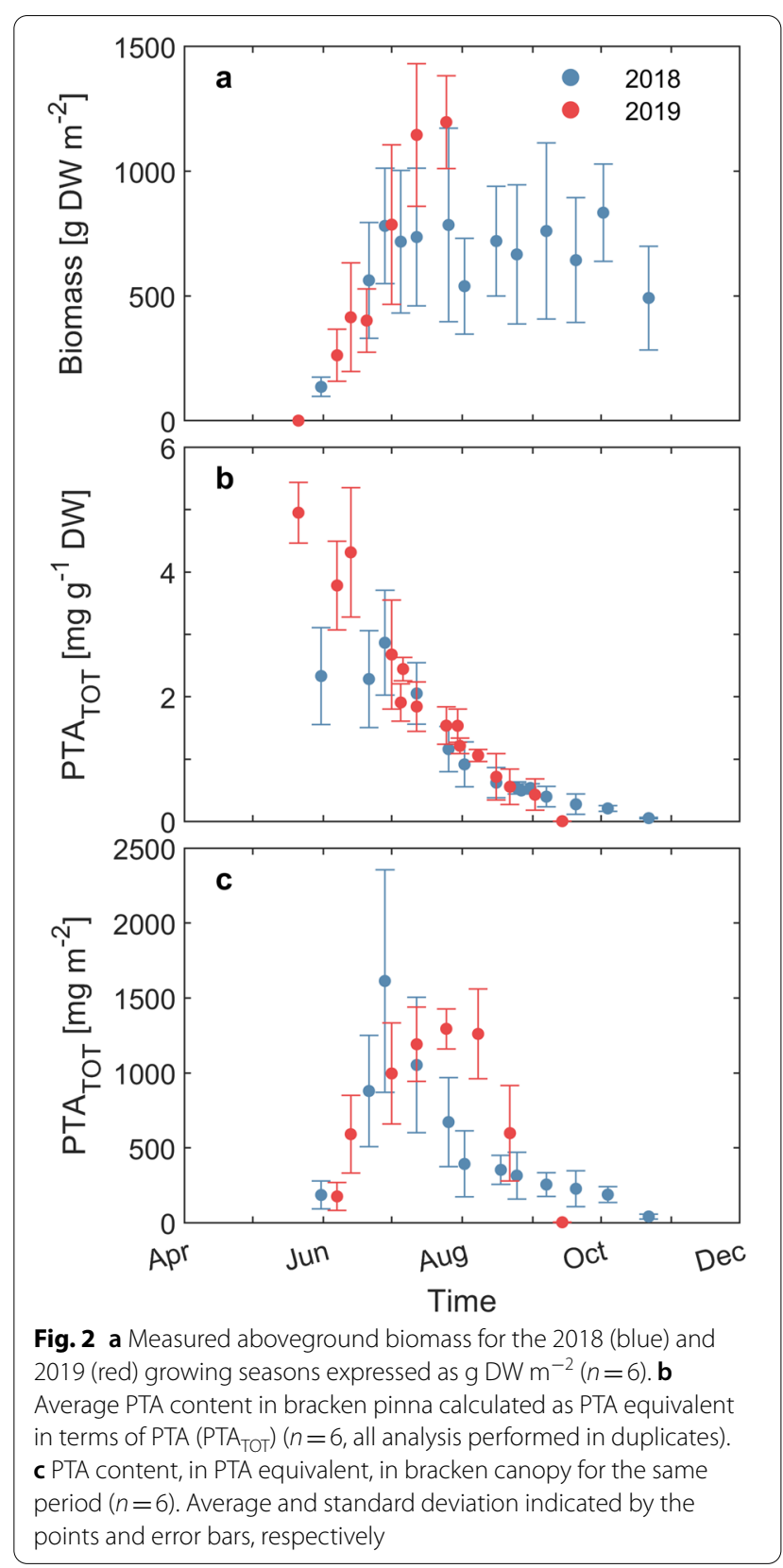




\section{PTA concentration in throughfall}

The quantification of PTA and PTB in the throughfall water from the wash off field experiments was carried out using the same method as described above. The samples from the events taking place in the 2018 growing season were analyzed by transformation to PTB and quantification by HPLC ("PTA determination in soil" section). Samples from the 2019 release experiments were quantified using a Waters Acquity UPLC I-class module equipped with a Waters Xevo TQD triple quadrupole mass spectrometer, with adjusted parameters based on the method by Kisielius et al. [17].

\section{Results and discussion}

\section{Bracken biomass development}

The development of bracken biomass followed the same trend in the 2018 and 2019 growing seasons. Emergence of fronds took place in May, reaching a maximum biomass in middle of July and followed by stabilization of the biomass until senescence (Fig. 2a). However, there are differences in the maximum value between 2018 and 2019 growing seasons, with a maximum of 785 and $1200 \mathrm{~g}$ DW $\mathrm{m}^{-2}$ for 2018 and 2019, respectively. The peak in biomass was reached earlier in 2018 (July) than in 2019, where the maximum was not reached before the monitoring came to a stop at the end of July due to a tilted bracken canopy caused by a heavy storm. The maximum weight of an independent frond was reached at end of July or beginning of August in both seasons, with masses of 173 and $247 \mathrm{~g}$ fresh weight (FW) for the 2018 and 2019 growing seasons, respectively.

Estimation of the subsurface biomass took place 1st July 2020 at the time that fronds reached maturity.

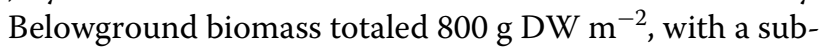
stantial variation between sites, which is normal due to stand heterogeneity. The biomass is somewhat lower than what reported from United Kingdom. However, sampling date is important considering that in July the rhizome biomass is expected to be at minimum, due to recent frond maturation and depletion of the rhizome nutritional storage [10]. Considering that bracken growth at initial stages is supported by root nutrient reserves, it is expected that biomass production within different years to be highly variable, even in the same location as it has been observed in this study (Fig. 2a).

\section{PTA production in bracken biomass}

The concentration of $\mathrm{PTA}_{\mathrm{TOT}}$ in the fronds $\left(\mathrm{mg} \mathrm{PTA}_{\mathrm{TOT}}\right.$ $\mathrm{g}^{-1} \mathrm{DW}$ ) shows the same pattern for both years, starting from the highest value at the beginning of the season and decreasing through the rest of the season until senescence (Fig. 2b). The maximum concentration of PTA in the biomass takes place at the beginning of the growing season, with values of 2.68 and $4.95 \mathrm{mg} \mathrm{g} \mathrm{DW}^{-1}$ for the 2018 and 2019 growing seasons, respectively. The decreasing trend is in agreement with observations from previous investigations $[22,33]$. One possible explanation is that PTA is produced during leaf initiation and then, concentrations decrease with time due to the combined effect of dilution in the growing biomass and release from the canopy by precipitation. This might also explain the drop in PTA content after the biomass has reached maturity, since the plant is not producing new biomass and hence, toxin in the canopy.

The total mass of $\mathrm{PTA}_{\text {TOT }}$ in the canopy reaches a maximum coinciding with the moment that maximum biomass is reached. The average maximum PTA mass in the canopy occurred in 2018, with values up to $1600 \mathrm{mg}$ PTA m${ }^{-2}$. However, the seasonal maximum took place at different times in both seasons, peaking in June and July for the 2018 and 2019 growing seasons, respectively. After peak concentrations were reached, a sudden decrease in the toxin content until senescence was recorded during both seasons (Fig. 2c). This decreasing trend observed in the toxin content taking place from time of maturity to senescence has been observed previously for studies in both UK and Denmark [33].

The similar curves for $\mathrm{PTA}_{\mathrm{TOT}}$ content in bracken for both seasons indicates that the toxin production in a certain bracken community and biotope, might be relatively stable between years. However, there were differences in the timing of the toxin maximum between years, probably influenced by the effect of environmental conditions on growth. The observed peak in toxin content took place in late June of 2018, during a period with high biomass and still high toxin concentrations, giving an estimated maximum of $2810 \mathrm{mg} \mathrm{PTA} \mathrm{TOT} \mathrm{m}^{-2}$. On the other hand, in 2019 the peak in toxin content took place later than in 2018 , at end of July, where the biomass reached its maximum. Therefore, particular production of new organs during the growing season might be correlated with toxin production $[40,41]$. This also explains the drastic decrease in the content in both years once the plant has reached maturity and there is no further net biomass production. This pattern of production of plant secondary metabolites linked with the production of new organs such as leaves, flowers or seeds, has been observed in other plants [5, 40, 42, 43].

Another factor contributing to the observed toxin content is the accumulated precipitation prior of sampling. The point with highest toxin mass at the end of June 2018 only had $21 \mathrm{~mm}$ of prior precipitation during the entire period (i.e., from 15th May), compared with $96 \mathrm{~mm}$ of rain during the same period in 2019. This observation supports the idea that PTA is produced during leaf initiation and that there is only a small fraction of PTA 

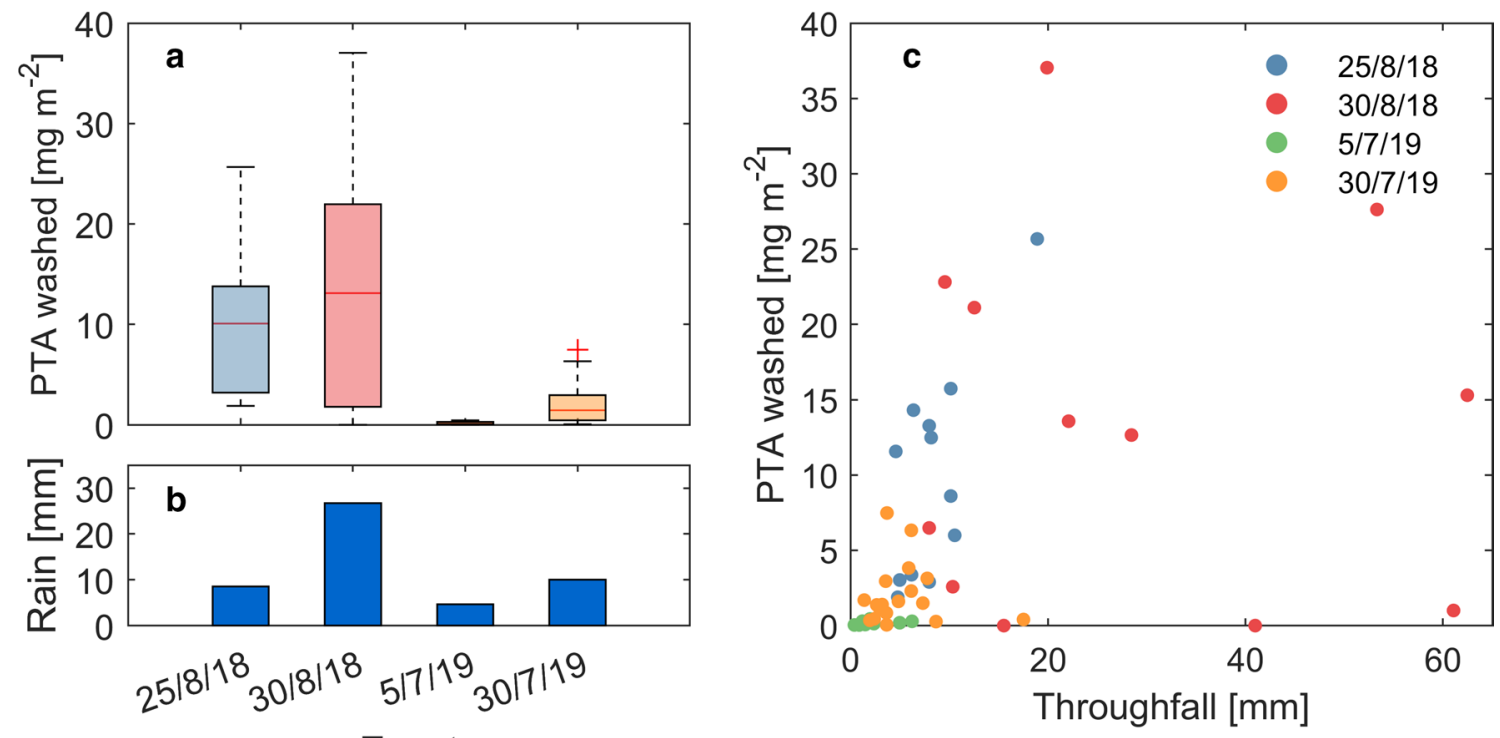

Fig. 3 a Estimated PTA masses washed off by precipitation during four different precipitation events. The middle of the box represents the median, the edge of the box the 25th and 75th percentile, while the errors bars denote the 10th and 90th percentiles. $n=12$ (2018) or 9 (2019). b Volume of precipitation recorded during the release events. $\mathbf{c}$ Estimated mass of PTA washed in the rain samples versus volume of throughfall collected in rain containers $(n=50)$

available for wash off that get depleted over time due to precipitation.

\section{Release of PTA from bracken to soil}

Precipitation events may cause PTA to be released at high concentrations, with PTA concentrations in the through-fall water ranging from 0 to $2530 \mu \mathrm{g} \mathrm{L}^{-1}$ for all samples and for all rain events (Additional file 1: Figure S8). Average concentrations for the individual rain events ranged from 102 to $1280 \mu \mathrm{g} \mathrm{L} \mathrm{L}^{-1}$, with an average PTA sample concentration of $663 \pm 700 \mu \mathrm{g} \mathrm{L} \mathrm{L}^{-1}$, calculated from all events. The average amounts of PTA washed from bracken leaves by precipitation during a single precipitation event ranged from 0.13 to $13.1 \mathrm{mg} \mathrm{PTA} \mathrm{m}^{-2}$, with an average PTA mass released from bracken during a single rain event of $6.23 \mathrm{mg} \mathrm{PTA} \mathrm{m}^{-2}$ (Fig. 3a).

The amounts of PTA washed off the canopy were positively correlated with the volume of precipitation and the canopy development stage (Fig. 3c). From the results, it is estimated that 0.04 to $0.65 \%$ of the PTA present in the pinna was washed per $\mathrm{mm}$ of incident rain, in accordance with previous studies [24, 25]. The results indicate that the PTA mass washed off the canopy is higher during precipitation events appearing late than early in the growing season, and this is most probably due to higher leaf area values at later stages (Fig. 3c). Another observation from the rain wash-off measurements, is that concentrations of PTA in the wash off were found to be inversely correlated with the volume of precipitation, hence indicating that the fraction of PTA available for wash off in bracken pinnae is not infinite (Additional file 1: Figure S8).

The fourth precipitation event took place during July or August, and therefore, the release event occurred with a fully developed canopy and biomass (Fig. 2a). Bracken canopy has a high water retention capacity, which has a strong influence on water dynamics in bracken populations, determining the amount of water intercepted and released as throughfall. For instance, during events with a low precipitation amount such as the event on 5th of July of 2019, the canopy intercepts most of the water and hence, barely any water was released from the canopy as throughfall (Fig. 3a). This is supported by the estimation of the canopy water retention capacity using the model of Pitman [44], which correlates leaf area index (LAI, e.g., area of leaves per surface area) with water holding capacity of the canopy. Bracken canopy with a LAI 4 is estimated to have a water retention capacity ranging from 0.6 to $1.9 \mathrm{~mm}$ [44]. Hence, during precipitation events not surpassing these values, water intercepted in the canopy would wash the PTA on the canopy but not transfer it to the soil, as it would not be any water dripping off the canopy. Water stagnated in the canopy might be also important contributing to the degradation of PTA on the canopy by hydrolysis or photolysis, hence explaining the presence of PTB in bracken. 
Table 2 Rate constants (k), coefficients of determination $\left(R^{2}\right)$ and half-lives $\left(t_{1 / 2}\right)$ for the dissipation of PTA in different Humleore soil horizons at two different moisture contents $\left(10^{\circ} \mathrm{C}\right)$

\begin{tabular}{|c|c|c|c|c|c|c|}
\hline \multirow[t]{2}{*}{ Hor } & \multicolumn{2}{|c|}{$k\left(h^{-1}\right) \times 10^{-2}$} & \multicolumn{2}{|l|}{$R^{2}$} & \multicolumn{2}{|l|}{$t_{1 / 2}(\mathrm{~h})$} \\
\hline & $\mathrm{pF} 1$ & $\mathrm{pF} 2$ & $\mathrm{pF} 1$ & $\mathrm{pF} 2$ & $\mathrm{pF} 1$ & $\mathrm{pF} 2$ \\
\hline$A_{1}$ & $13.1 \pm 0.79$ & $20.8 \pm 1.24$ & 0.993 & 0.990 & $5.3 \pm 0.32$ & $3.3 \pm 0.2$ \\
\hline $\mathrm{A}_{2}$ & $1.6 \pm 0.08$ & $2.5 \pm 0.14$ & 0.989 & 0.987 & $43.6 \pm 2.2$ & $28.1 \pm 1.6$ \\
\hline$A E$ & $1.0 \pm 0.07$ & $1.1 \pm 0.11$ & 0.970 & 0.938 & $73.0 \pm 5.3$ & $65.4 \pm 6.8$ \\
\hline
\end{tabular}

Rates and half-lives are expressed as value \pm standard error of the regression equation

Furthermore, there are some less obvious factors contributing to the total mass of PTA being released such as the number of antecedent dry days before precipitation. Results from the release events in this study suggest that there is only a certain pool of PTA to be washed off by precipitation, rather than the total toxin content in the plant. A period with continuous precipitation is expected to deplete the available PTA pool in the canopy. Hence, the amount of PTA washed per mm of rain will be extremely variable between locations as well as within different years due to widely different precipitation patterns, calling for caution in the interpretation of the release data (Fig. 3b). Another important remark is that other glycosides produced by bracken fern, e.g., CAU and PTE, were detected at relatively high concentrations compared with PTA in the throughfall (Additional file 1: Figure S10). The median relative abundance for CAU and PTE in the precipitation event taking place on $30^{\text {th }}$ July 2019 was 38 and $26 \%$, respectively. This finding suggests that all the glycosides produced by bracken can be equally washed off the canopy like PTA.

\section{Degradation of PTA in soil}

Degradation kinetics of PTA in soil materials could be successfully fitted as a first-order reaction with respect to PTA. Results show that PTA dissipates in the soil rapidly, with half-lives ranging from 3.3 to $84.5 \mathrm{~h}$ (Table 2). A tenfold decrease in degradation rates with depths was recorded when comparing horizon $\mathrm{A}_{1}$ and $\mathrm{AE}$, showing a strong influence of depth on degradation of PTA in soils. On the contrary, soil moisture had a negative effect on degradation rates for all horizons, with 9-27\% slower degradation rates at pF 1 compared with pF 2 .

Results are in agreement with previous studies on PTA degradation and with similar effects of the influence of soil depth [26, 27, 37]. The marked decrease in rates with depth, indicates that degradation of PTA is mainly driven by microbial degradation, as seen in previous studies with sterile soil in acidic $\mathrm{pH}$ ranges similar to this study [27].

The contribution of abiotic hydrolysis to the overall degradation of PTA is rather small considering the model proposed by Ayala-Luis et al., which estimates hydrolysis rates of PTA based on $\mathrm{pH}$ of the solution. Using the $\mathrm{pH}$ from each horizon and accounting for the influence of temperature, abiotic hydrolysis is estimated to contribute just with 1 to $4.1 \%$ of the overall degradation of PTA observed [28]. Even though hydrolysis rates are two orders of magnitude lower than microbial degradation, it will gain importance at determining the fate of PTA in groundwater in the long term as microbial activity is much lower in subsoils and in aquifers.

\section{PTA in soil solution}

Results from the suction cells show that PTA is present in the soil mostly during the growing season and beginning of autumn. On the other hand, PTB was detected from the beginning of the monitoring in March until autumn, suggesting that there is an unidentified input of PTA prior to the start of the season, given the rapid degradation of PTA and PTB in soils as described above (Fig. 4). Concentrations of PTA and PTB in the soil pore water increased over time during the growing period, showing a strong positive correlation with the development of bracken biomass. Median concentrations in the pore water at $50 \mathrm{~cm}$ depth were, only considering positives, 40 and $88 \mathrm{ng} \mathrm{L}^{-1}$ for PTA and PTB, respectively. Concentrations in the soil showed extreme variability, with values differing by several orders of magnitude for samples taken the same day. Observed concentrations in the soil solution indicates that leaching of PTA takes place in form of pulses connected to specific precipitation events, considering that PTA degrades rapidly in soils. This leaching pattern has been observed for PTA in surface waters, as well as for the case of pesticides under similar environmental conditions [24, 45].

Peak concentrations in soil solution were observed at the end of July, with observed values up to 4820 and $3500 \mathrm{ng} \mathrm{L}^{-1}$ for PTA and PTB, respectively. The average concentrations for that particular sampling day were also the maximum observed during the entire monitoring period, with values of 1660 and $2410 \mathrm{ng} \mathrm{L}^{-1}$ for PTA and PTB, respectively. After this period, there is an apparent decrease in concentrations until October, but uncertain due to the limited number of samples during the dry 


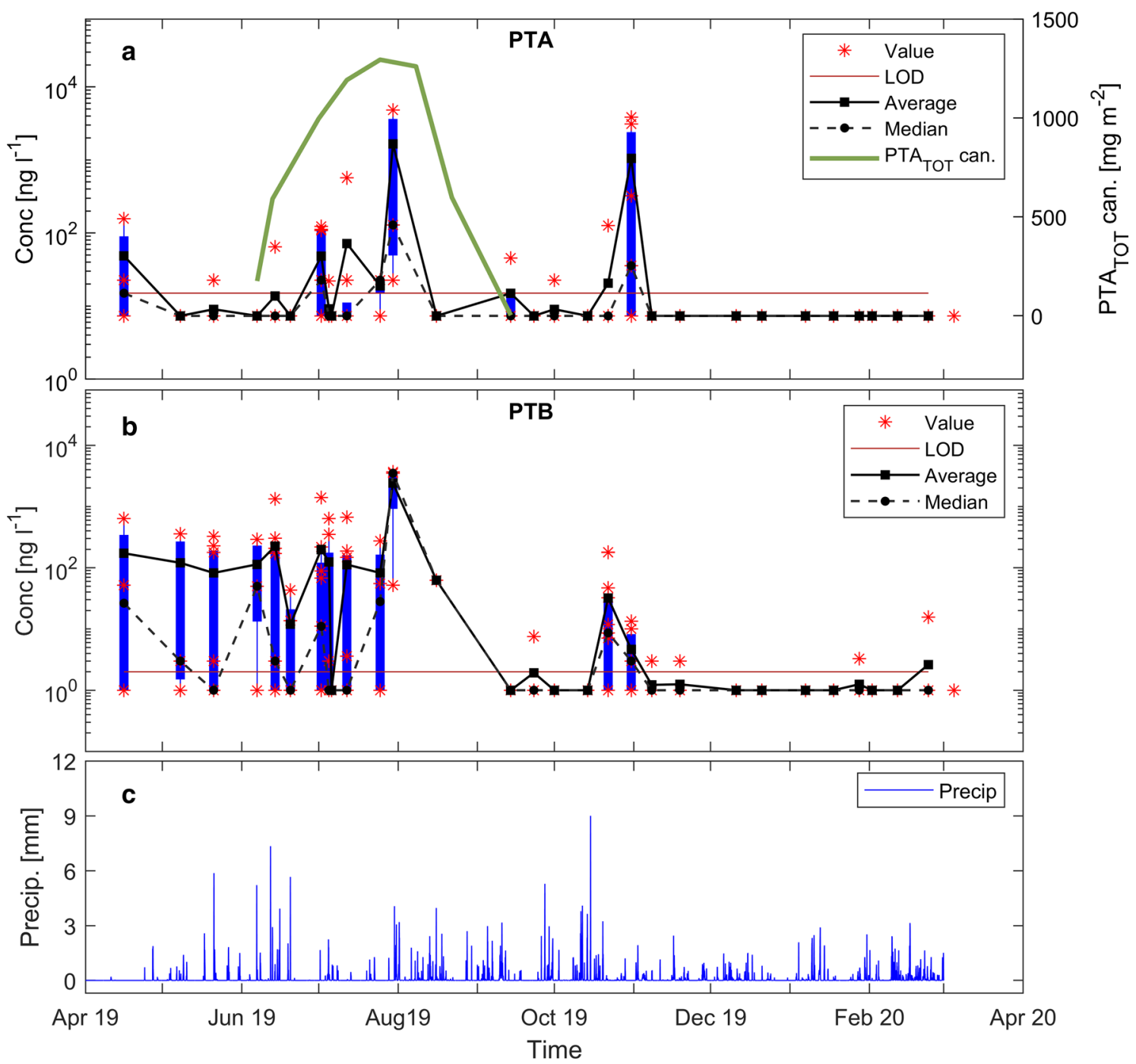

Fig. 4 Concentrations of PTA (a) and PTB (b) in soil pore water at $50 \mathrm{~cm}$ depth under bracken recorded in the period from March 2019 until March

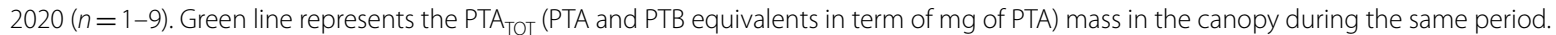
c Precipitation recorded for 10 min interval in the nearest weather station during the same period (bottom). Boxplots represent the 25th and 75th percentile, while the whiskers represent the 10th and 90th percentile. LOD shown by red line, while red stars represent observed values of measurements. Dotted line represents the median concentration for each sampling day, while average is indicated by the black line

period. This decrease in soil pore water concentrations from July correlates with the decrease in toxin content in the canopy (Fig. 2c). A second high pulse event took place at the end of October after a rainy period. Concentrations of PTA peaked with $3850 \mathrm{ng} \mathrm{L^{-1 }}$, while PTB concentrations only reached up to $180 \mathrm{ng} \mathrm{L}^{-1}$. Average concentrations for this pulse event were 1050 and $32 \mathrm{ng}$ $\mathrm{L}^{-1}$ for PTA and PTB, respectively.

The ratios of PTA and PTB concentrations gives an indication of residence time of PTA in the soil, given the assumption that PTB is produced as a primary degradation product of PTA. Throughout the monitoring, PTA was predominantly lower or at the same concentration range as PTB, as PTA is transformed into PTB rapidly in soils (Table 2). Note that PTB also degrades in soils, so the presence of PTB indicates a relatively fresh input of PTA into the soil system [29]. During the pulse event taking place at the end of October, PTA concentrations were 21-fold higher than PTB. This indicates that there is a source of PTA able to release considerable amounts into the soil in late October. Bracken at that time in 2019 had become litter and PTA contents in the biomass were under the LOD, since the middle of September (Fig. 2c). Interestingly, before the sampling date, the first two 
nights of frost with a minimum temperature of $-5{ }^{\circ} \mathrm{C}$ had appeared (Additional file 1).

Frost might be an important factor contributing to leaching as frost results in lysis of cells [46]. Applying this to the case of bracken, it explains the total depletion of PTA in bracken material at the end of the season, indicating that all PTA is either released or degraded rapidly after senescence. The formation of frost during the winter period also contribute to the progressive compaction of the litter layer, and after every thawing cycle, the content of soluble compounds in the litter is released to pore water. Moreover, at the beginning of autumn is when PTA contents in the rhizomes are at its maximum, and therefore, rhizome and/or root exudation cannot be excluded as another source of PTA [31]. Release of PTA from decaying bracken rhizomes is an unknown and yet not quantified process, and it has the potential to be a major input to the soil, considering both biomass and PTA content of rhizomes [31].

Other important aspects to consider are the conditions of the soil in the beginning of autumn, with increasing water saturation and low soil temperatures. Hence, during the autumn period, residence time of PTA in the soil is shorter than in summer, giving less time for PTA to dissipate. Moreover, low soil temperatures also contributes to decrease in rates from both microbial degradation and hydrolysis [28]. Taking into consideration all points mentioned above, we identify the period at the beginning of autumn as the highest risk of release of PTA leaching to freshwaters.

A higher sampling frequency will improve our understanding of PTA dynamics in the soil-plant-water continuum, and lead to more accurate estimation of mass fluxes between the different environmental compartments. The dataset generated in this study can be used as the validation dataset for the model of Garcia-Jorgensen et al. This model will serve as a valuable tool for elucidating the leaching fluxes and peak concentrations during pulse events and to accurately assess the risk of waterbodies pollution by bracken toxins.

\section{Conclusion}

This 2-year monitoring study connects production of bracken biomass, production of PTA in the canopy, release by precipitation and PTA concentrations in soil solution. The mass of $\mathrm{PTA}_{\text {TOT }}$ in the canopy peaked at $1600 \mathrm{mg} \mathrm{m}^{-2}$ in July, coinciding with the moment, where the maximum biomass was reached. Production of PTA in bracken was proportional to the production of new biomass. Once there was no net production of biomass, $\mathrm{PTA}_{\mathrm{TOT}}$ in the canopy decreased progressively towards the end of the growing season.
Wash off by precipitation was the most important input of PTA to the soil, with estimated masses of PTA transfer to the soil up to $13.1 \mathrm{mg} \mathrm{m}^{-2}$ during a single rain event. The total mass of PTA washed was positively correlated with the volume of precipitation and development stage, showing an influence of canopy structure on the release of PTA. The fraction of PTA washed off by $\mathrm{mm}$ of rain is estimated to be, on average, $0.2 \%$ of the total content in the canopy. Degradation of PTA in the soil was fast and strongly decreased by soil depth, with half-lives between 3.3 and 73 days for upper and lower soil horizons, respectively.

Leaching of PTA takes place as pulses related to specific rain events, with peak concentrations in the soil pore water solution up to $4.8 \mu \mathrm{g} \mathrm{L}^{-1}$. Observation of a PTA pulse event in October indicates that there was a fresh input of PTA to the soil taking place in autumn, suggesting the presence of another PTA pool apart from the living canopy. Based on the results, we conclude that leaching of PTA takes place throughout the growing season and into the autumn, with high variability in concentrations due to the pulse-type transport and substantial degradation of PTA in the soil.

\section{Abbreviations}

PTA: Ptaquiloside; WHO/IARC: World Health Organization/International Agency for Research of Cancer; CAU: Caudatoside; PTE: Ptesculentoside; PTB: Pterosin

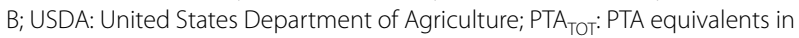
term of mg of PTA; LOD: Limit of detection; LOQ: Limit of quantification; HPLC: High-performance liquid chromatography; LC-MS: Liquid chromatography mass-spectrometry; LAl: Leaf area index.

\section{Supplementary Information}

The online version contains supplementary material available at https://doi. org/10.1186/s12302-021-00484-0.

Additional file 1. Site description, monitoring setup and results.

\section{Acknowledgements}

The authors want to acknowledge Anita Sandager and Birgitte B. Rasmussen for their technical assistance during the study. Moreover, we appreciate Humleore Skovdistrikt and Naturestyrelsen for granting permission for sampling and monitoring.

\section{Authors' contributions}

DBGJ: Conceptualization, methodology, investigation, writing —original draft. ED: Supervision, conceptualization, methodology, data curation, writingreview and editing. VK: Technical assistance, resources, writing —review. MR: Technical assistance, investigation, writing —review. LHR: Technical assistance, resources, writing — review. BJW: Technical assistance, writing-review. $\mathrm{HCBH}$ : Supervision, conceptualization, methodology, writing —review and editing. All authors read and approved the final manuscript.

\section{Funding}

This project has received funding from the European Union's Horizon 2020 research and innovation programme under the Marie Sklodowska-Curie Grant Agreement No. 722493 (NaToxAq). 


\section{Availability of data and materials}

The datasets used and analyzed during this study, and not already included in Additional file 1 materials, are available from the corresponding author on reasonable request.

\section{Declarations}

Ethics approval and consent to participate

Not applicable.

\section{Consent for publication}

Not applicable.

\section{Competing interests}

The authors declare no competing interests.

\section{Author details}

${ }^{1}$ Department of Plant and Environmental Sciences, University of Copenhagen, Thorvaldsensvej 40, 1871 Frederiksberg, Denmark. ${ }^{2}$ Department of Technology, University College Copenhagen, Sigurdsgade 26, 2200 Copenhagen, Denmark.

Received: 21 December 2020 Accepted: 16 March 2021

Published online: 08 April 2021

\section{References}

1. Günthardt BF, Schönsee CD, Hollender J, Hungerbühler K, Scheringer M, Bucheli TD (2020) "Is there anybody else out there?" - first insights from a suspect screening for phytotoxins in surface water. CHIMIA Int J Chem 74(3):129-135. https://doi.org/10.2533/chimia.2020.129

2. Bucheli TD (2014) Phytotoxins: environmental micropollutants of concern? Environ Sci Technol 48(22):13027-13033. https://doi.org/10.1021/ es504342W

3. Günthardt BF, Hollender J, Hungerbühler K, Scheringer M, Bucheli TD (2018) Comprehensive toxic plants-phytotoxins database and its application in assessing aquatic micropollution potential. J Agric Food Chem 66(29):7577-7588. https://doi.org/10.1021/acs.jafc.8b01639

4. Clauson-Kaas F, Jensen PH, Jacobsen OS, Juhler RK, Hansen HCB (2014) The naturally occurring carcinogen ptaquiloside is present in groundwater below bracken vegetation. Environ Toxicol Chem 33(5):1030-1034. https://doi.org/10.1002/etc.2533

5. Hama JR, Strobel BW (2019) Pyrrolizidine alkaloids quantified in soil and water using UPLC-MS/MS. RSC Adv 9(52):30350-30357. https://doi.org/ 10.1039/c9ra05301h

6. Tung K-K, Chan CK, Zhao Y, Chan KKJ, Liu G, Pavlovic NM, Chan W (2019) Occurrence and environmental stability of aristolochic acids in groundwater collected from serbia: links to human exposure and balkan endemic nephropathy. Environ Sci Technol 54(3):1554-1561. https://doi. org/10.1021/acs.est.9b05337

7. Scavo A, Abbate C, Mauromicale G (2019) Plant allelochemicals: agronomic, nutritional and ecological relevance in the soil system. Plant Soil 442(1-2):23-48. https://doi.org/10.1007/s11104-019-04190-y

8. Kobayashi K (2004) Factors affecting phytotoxic activity of allelochemicals in soil. Weed Biol Manag 4(1):1-7. https://doi.org/10.1111/j.1445-6664. 2003.00112.x

9. Page C (1976) The taxonomy and phytogeography of bracken-a review. Bot J Linn Soc 73(1-3):1-34

10. Marrs RH, Watt AS (2006) Biological flora of the British Isles: Pteridium aquilinum (L.) Kuhn. J Ecol 94(6):1272-1321. https://doi.org/10.1111/j. 1365-2745.2006.01177x

11. Duc ML, Pakeman R, Marrs R (2003) Changes in the rhizome system of bracken subjected to long-term experimental treatment. J Appl Ecol 40(3):508-522

12. Ssali F, Moe SR, Sheil D (2019) The differential effects of bracken (Pteridium aquilinum (L.) Kuhn) on germination and seedling performance of tree species in the African tropics. Plant Ecol 220(1):41-55. https://doi.org/10. 1007/s11258-018-0901-8
13. Dolling A, Zackrisson O, Nilsson M-C (1994) Seasonal variation in phytotoxicity of bracken (Pteridium aquilinum L. Kuhn). J Chem Ecol 20(12):3163-3172. https://doi.org/10.1007/bf02033718

14. International Agency for Research on Cancer (IARC) (1998) Summaries \& evaluations, bracken fern (Pteridium aquilinum) and some of its constituents. http://www.inchem.org/documents/iarc/vol40/brackenfern.html

15. Vetter J (2009) A biological hazard of our age: bracken fern [Pteridium aquilinum (L.) Kuhn] — a review. Acta veterinaria Hungarica (Budapest. 1983) 57(1):183-196. https://doi.org/10.1556/AVet.57.2009.1.18

16. Potter DM, Baird MS (2000) Carcinogenic effects of ptaquiloside in bracken fern and related compounds. Br J Cancer 83(7):914-920. https:// doi.org/10.1054/bjoc.2000.1368

17. Kisielius V, Lindqvist DN, Thygesen MB, Rodamer M, Hansen HCB, Rasmussen LH (2020) Fast LC-MS quantification of ptesculentoside, caudatoside, ptaquiloside and corresponding pterosins in bracken ferns. J Chromatogr B 1138:121966. https://doi.org/10.1016/j.jchromb.2019.121966

18. Castillo UF, Ojika M, Sakagami Y, Wilkins AL, Lauren DR, Alonso-Amelot M, Smith BL (2000) Isolation and structural determination of three new toxic illudane-type sesquiterpene glucosides and a new protoilludane sesquiterpene glucoside from Pteridium aquilinum var. caudatum. Bracken fern: toxicity, biology, and control. Int Bracken Group Spec Publ 4:55-59. https:// doi.org/10.1021/jf100267a

19. Fletcher MT, Reichmann KG, Brock IJ, McKenzie RA, Blaney BJ (2011) Residue potential of norsesquiterpene glycosides in tissues of cattle fed austral bracken (Pteridium esculentum). J Agric Food Chem 59(15):85188523. https://doi.org/10.1021/jf201342t

20. Fletcher MT, Brock IJ, Reichmann KG, McKenzie RA, Blaney BJ (2011) Norsesquiterpene glycosides in bracken ferns (Pteridium esculentum and Pteridium aquilinum subsp. wightianum) from Eastern Australia: reassessed poisoning risk to animals. J Agric Food Chem 59(9):5133-5138. https://doi.org/10.1021/jf104267c

21. Kisielius V (2020) Toxic secondary metabolites from plants: a new aspect of water quality. (PhD Thesis). University College Copenhagen, Copenhagen

22. Rasmussen LH, Kroghsbo S, Frisvad JC, Hansen HCB (2003) Occurrence of the carcinogenic Bracken constituent ptaquiloside in fronds, topsoils and organic soil layers in Denmark. Chemosphere 51(2):117-127. https://doi. org/10.1016/s0045-6535(02)00694-x

23. Jensen PH, Jacobsen OS, Hansen HCB, Juhler RK (2008) Quantification of ptaquiloside and pterosin $B$ in soil and groundwater using liquid chromatography-tandem mass spectrometry (LC-MS/MS). J Agric Food Chem 56(21):9848-9854. https://doi.org/10.1021/jf801986u

24. Clauson-Kaas F, Ramwell C, Hansen HCB, Strobel BW (2016) Ptaquiloside from bracken in stream water at base flow and during storm events. Water Res 106:155-162. https://doi.org/10.1016/j.watres.2016.09.049

25. Rasmussen LH, Jensen LS, Hansen HCB (2003) Distribution of the carcinogenic terpene ptaquiloside in bracken fronds, rhizomes (Pteridium aquilinum), and litter in Denmark. J Chem Ecol 29(3):771-778. https://doi. org/10.1023/a:1022885006742

26. Rasmussen LH, Bruun Hansen HC, Lauren D (2005) Sorption, degradation and mobility of ptaquiloside, a carcinogenic Bracken (Pteridium sp.) constituent, in the soil environment. Chemosphere 58(6):823-835. https:// doi.org/10.1016/j.chemosphere.2004.08.088

27. Engel P, Brandt KK, Rasmussen LH, Ovesen RG, Sorensen J (2007) Microbial degradation and impact of Bracken toxin ptaquiloside on microbial communities in soil. Chemosphere 67(1):202-209. https://doi.org/10. 1016/j.chemosphere.2006.08.025

28. Ayala-Luis KB, Hansen PB, Rasmussen LH, Hansen HCB (2006) Kinetics of ptaquiloside hydrolysis in aqueous solution. Environ Toxicol Chem 25(10):2623. https://doi.org/10.1897/05-695r.1

29. Skourti-Stathaki E, Clauson-Kaas F, Brandt KK, Rasmussen LH, Hansen HCB (2016) Dissipation of pterosin B in acid soils-tracking the fate of the bracken fern carcinogen ptaquiloside. Chemosphere 165:453-459. https://doi.org/10.1016/j.chemosphere.2016.09.050

30. Garcia Jorgensen DB, Hansen HCB, Abrahamnsen P, Diamantopoulos E (2020) A novel model concept for modelling the leaching of natural toxins: results for the case of ptaquiloside. Environ Sci Process Impacts 22(8):1758-1779. https://doi.org/10.1039/d0em00182a

31. Rasmussen LH, Donnelly E, Strobel BW, Holm PE, Hansen HC (2015) Land management of bracken needs to account for bracken carcinogens-a 
case study from Britain. J Environ Manage 151:258-266. https://doi.org/ 10.1016/j.jenvman.2014.12.052

32. Zaccone C, Cavoski I, Costi R, Sarais G, Caboni P, Traversa A, Miano TM (2014) Ptaquiloside in Pteridium aquilinum subsp. aquilinum and corresponding soils from the South of Italy: influence of physical and chemical features of soils on its occurrence. Sci Total Environ 496:365-372. https:// doi.org/10.1016/j.scitotenv.2014.07.046

33. Rasmussen L, Hansen H (2004) Growth of Bracken in Denmark and the content of ptaquiloside in fronds. Poisonous Plants Related Toxins. https://doi.org/10.1079/9780851996141.0354

34. Schoeneberger PJ, Wysocki DA, Benham EC (2012) Field book for describing and sampling soils. Government Printing Office, Washington

35. USDA, N (2010) Keys to soil taxonomy. Soil Survey Staff, Washington

36. Clauson-Kaas F, Hansen HC, Strobel BW (2016) UPLC-MS/MS determination of ptaquiloside and pterosin B in preserved natural water. Anal Bioanal Chem 408(28):7981-7990. https://doi.org/10.1007/s00216-016-9895-z

37. Ovesen RG, Rasmussen LH, Hansen HCB (2008) Degradation kinetics of ptaquiloside in soil and soil solution. Environ Toxicol Chem 27(2):252. https://doi.org/10.1897/07-324r.1

38. Rasmussen LH, Pedersen HA (2017) Screening for ptaquiloside in ferns: using herbarium specimens for qualitative mapping purposes. Phytochem Anal 28(6):575-583. https://doi.org/10.1002/pca.2707

39. Skrbic N, Kisielius V, Pedersen AK, Christensen SC, Hedegaard MJ, Hansen HCB, Rasmussen LH (2020) Occurrence of carcinogenic illudane glycosides in drinking water wells. https://doi.org/10.21203/rs.3.rs-103108/v1 (unpublished)

40. Oliveira CS, Salino A, Paiva EAS (2017) Colleters in Thelypteridaceae: unveiling mucilage secretion and its probable role in ferns. Flora 228:65-70. https://doi.org/10.1016/j.flora.2017.01.009
41. Rodriguez AM, Derita MG, Borkosky SA, Socolsky C, Bardón A, Hernández MA (2018) Bioactive farina of Notholaena sulphurea (Pteridaceae): Morphology and histochemistry of glandular trichomes. Flora 240:144-151. https://doi.org/10.1016/j.flora.2018.01.008

42. Rios-Estepa R, Turner GW, Lee JM, Croteau RB, Lange BM (2008) A systems biology approach identifies the biochemical mechanisms regulating monoterpenoid essential oil composition in peppermint. Proc Natl Acad Sci 105(8):2818-2823. https://doi.org/10.1073/pnas.0712314105

43. Hama JR, Strobel BW (2020) Natural alkaloids from narrow-leaf and yellow lupins transfer to soil and soil solution in agricultural fields. Environ Sci Eur. https://doi.org/10.1186/s12302-020-00405-7

44. Pitman JI (1989) Rainfall interception by bracken in open habitats-relations between leaf area, canopy storage and drainage rate. J Hydrol 105(3-4):317-334. https://doi.org/10.1016/0022-1694(89)90111-X

45. Rosenbom AE, Olsen P, Plauborg F, Grant R, Juhler RK, Brüsch W, Kjær J (2015) Pesticide leaching through sandy and loamy fields-long-term lessons learnt from the Danish Pesticide Leaching Assessment Programme. Environ Pollut 201:75-90. https://doi.org/10.1016/j.envpol.2015. 03.002

46. Shehadul Islam M, Aryasomayajula A, Selvaganapathy PR (2017) A review on macroscale and microscale cell lysis methods. Micromachines 8(3):83. https://doi.org/10.3390/mi8030083

\section{Publisher's Note}

Springer Nature remains neutral with regard to jurisdictional claims in published maps and institutional affiliations.

\section{Submit your manuscript to a SpringerOpen ${ }^{\circ}$ journal and benefit from:}

- Convenient online submission

- Rigorous peer review

- Open access: articles freely available online

- High visibility within the field

- Retaining the copyright to your article

Submit your next manuscript at $\boldsymbol{\nabla}$ springeropen.com 